\title{
EGFR NP_005219.2:p.D761_E762insEAFQ
}

National Cancer Institute

\section{Source}

National Cancer Institute. EGFR NP 005219.2:p.D761 E762insEAFQ. NCI Thesaurus.

Code $C 98601$.

An insertion of the amino acid sequence glutamic acid-alanine-phenylalanine-glutamine between the aspartic acid at position 761 and the glutamic acid at position 762 of the epidermal growth factor receptor protein. 